\title{
Work functions shaping the ability to innovate: insights from the case of the safety engineer
}

\author{
Fredrik Asplund $^{1} \mathbb{D} \cdot$ Pernilla Ulfvengren $^{2}$
}

Received: 18 March 2019 / Accepted: 21 November 2019 / Published online: 30 November 2019

(c) The Author(s) 2019

\begin{abstract}
To perform as intended, firms are divided into work functions that contribute to the behaviour-shaping constraints under which individuals build their skills, knowledge and networks. These in turn provide a specialized perspective on organisational structure and culture. In a mixed methods study involving interviews and statistical analyses, we investigate whether a work function can thereby affect individuals' innovation foci and efficacy. Safety engineers, central to firms developing Cyber-Physical Systems (CPS), are shown to play a significant role in identifying and supporting viable innovation related to organisational aspects. Results indicate that safety engineers could use the firm's collaborative innovation process to facilitate organisational learning, helping different work functions come together to construct working practices aligned with the organisational values of the firm. This is explained by their understanding of safety culture-a specialized understanding of organisational culture and complexity provided by their work function. We conclude that work functions that provide their members with a perspective well aligned with their firm's organisational values can instil the ability to identify and support organisational innovation. This suggests that safety engineers in CPS domains could be effective in a mediatory role, facilitating innovative changes to organisational structures and processes when introducing and operating safety management systems. Stronger aspects of organisational liaising and systems thinking could reinforce this ability-the former by a wider scope and motivation leading to an increased skill in communicating with dissimilar individuals, and the latter by providing the skills and tools needed to analyse the politics of complex organisations.
\end{abstract}

Keywords Administrative innovation $\cdot$ Behaviour-shaping constraints $\cdot$ Cognitive systems engineering $\cdot$ Organisational culture $\cdot$ Organisational learning $\cdot$ Safety engineering

\section{Introduction}

"Our people are our greatest asset..." This is a common and perhaps worn out statement by many firms. However, in the studies of knowledge-intensive contexts it is a generally accepted truth. After all, when the engineers in a Research and Development department leave, the remaining office space and computers are of little value on their own. From a knowledge-based perspective, superior access and ability to integrate knowledge are the most important ways to achieve competitive advantage in knowledge-intensive contexts

Fredrik Asplund

fasplund@kth.se

1 Department of Machine Design, KTH Royal Institute of Technology, Stockholm, Sweden

2 Department of Industrial Economics and Management, KTH Royal Institute of Technology, Stockholm, Sweden
(Grant 1996). Therefore, many firms put considerable effort into fostering an innovative climate where ideas which may lead to a competitive advantage can be identified, developed and implemented. The properties of individual employees, organisational structures and the strategies of firms are all important factors in establishing and maintaining such an innovative and creative climate (Cohen and Levinthal 1990; Amabile 1997; Nooteboom 2000; Pyka 2002; Ozman 2009; West and Bogers 2014; Aral 2016). While the characteristics of the organisation and the individual are arguably related, this relationship and their collective effect have not received much attention in regard to networks (Aalbers et al. 2013) and work design (Foss et al. 2009). However, evidence suggests that the relationship between individual characteristics, such as knowledge sourcing and network centrality differs across different functional roles (Teigland and Wasko 2009) in knowledge-intensive work systems. 
In the discourse on complex sociotechnical systems with humans working in a technology-intensive and often high-risk context, this relationship is a central assumption (Meister 1999). The success of quality movement is thus explained by increased horizontal communication, empowerment and participation that facilitates autonomy and the aggregation of know-how through cross-functional work groups (McDonald and Ulfvengren 2019). This has been studied extensively in operational contexts where Cyber-Physical Systems (CPS) are used to handle interactions between marine vessels, traffic on highways or processes in factories. It is here argued that the same mechanisms are also in play in the work systems that develop CPS, i.e., at the firms that develop and manufacture CPS products such as aeroplanes, power plants, marine vessels and associated components. A central explanatory concept to this is behaviour-shaping constraints: that the structure of the work domain, work tasks and strategies, social and organizational factors, worker competencies and physical environments all constrain workers' ability to perform their work with the required flexibility (Rasmussen et al. 1994b). In the field of cognitive systems engineering Rasmussen et al. (1994a) and Vicente (1999) thus argue for the development of sociotechnical systems which have less constraints. This should provide an advantage through more autonomous work. With regard to the systems engineering of such complex, technology intensive systems, the social component is not as thoroughly addressed in comparison to descriptive and prescriptive work processes (McDonald 2015). This is the basis for an on-going call for "humanization" of the field of system engineering towards human-system integration (Boy 2017). This effort is also aligned with other initiatives to integrate sustainability and social sciences to more holistic sociotechnical system engineering (De Weck et al. 2011).

Arguably, management studies and cognitive systems engineering thus overlap in the idea that groups centred on different functional roles can shape individuals' networking and behaviour to such a degree that it affects their knowledge transfer efficacy and innovativeness. While these groups can be seen as intra-organisational Communities of Practice (CoP) (Brown and Duguid 2001), we use the term work functions for them in this paper since $\mathrm{CoP}$ can have wider inter-organisational implications. Management studies thus suggest that work functions should be able to influence their members' ability to innovate directly (by shaping networking and behaviour) and indirectly (by providing knowledge in relation to networking and behaviour that will shift the foci when innovating). This should in turn provide system engineering with opportunities for shaping innovation in a beneficial direction: firms should be able to identify and support work functions likely to successfully improve innovation foci of special interest, and work functions should be able to focus their efforts on innovation most likely to successfully improve their working environment and further their work goals.

Management studies thus provide a relevant frame of reference, which is useful as cognitive systems research in the CPS domain has largely focused on contexts that are related, but distinct, from that of this study. However, the discourse on cognitive systems engineering still provides a link that allows us to form a perspective on how to approach the redesign of sociotechnical systems to improve the situation. This paper thus outlines a study of the nexus of these two discourses to discern whether work functions can become especially able to identify viable changes not only to improve their work tasks, but also the behaviour-shaping constraints that limits them.

The paper starts by detailing findings from relevant discourses and tying them together in an analytical framework. This allows us to propose two hypotheses for a specific work function: that safety engineers will-by transferring and transforming knowledge across boundaries between organisational units and engineering disciplines-facilitate the realization of product innovation [innovation that changes the artefacts offered by an organization (Francis and Bessant 2005)]; and that safety engineers will-through their specialized understanding of organisational culture-facilitate the realization of administrative innovations [process innovations concerned with organisational structure and administrative processes (Gopalakrishnan and Damanpour 1994)]. The methodology of the study is then described, including details regarding a quantitative study of the actions of, and interviews with, participants of a firm-internal innovation system. Finally, the results are presented, discussed and summarized. Using our insights from the safety engineering work function, we conclude that the tasks carried out by work functions may provide and shape the knowledge, skills and networks their members hold to the degree that it can make them especially apt at identifying and supporting administrative innovation; and we point at further strengthening of organisational liaising and systems thinking to help develop this ability. This specifically suggests that safety engineers in Cyber-Physical Systems (CPS) domains (Törngren et al. 2017) are well placed to mediate during the introduction and operation of safety management systems.

\section{Theoretical framework}

The following section starts by describing two discourses on key organisational aspects relevant to innovation. The findings are related to a sociotechnical perspective to posit two hypotheses related to how the tasks of the safety engineer work function influence the ability and focus of its members in innovation activities. 


\subsection{Boundary spanning and innovation}

Burt's (2004) theory on structural holes suggests that those who single-handedly connect otherwise isolated network parts receive information early, and this gives them an advantage in identifying and developing good ideas. Therefore, people or organisations that connect others across boundaries should have more opportunities to innovate. These so called boundary spanners or knowledge brokers tie together networks formed within domains, professions and organisations (Haas 2015). Organisations need to provide extensive support for the access to and manipulation of knowledge if their employees are to achieve technology brokering (Hargadon and Sutton 1997). Technology brokering services can be diverse, with individuals handling, for instance, information exchange, market access and coordination when spanning boundaries, both internal and between organisations (Haas 2015). Transferring knowledge across boundaries is thus, formally or informally, a part of many roles.

In regard to boundary spanning the gatekeeper role is one of the most studied. This role brings knowledge from external sources into an organisation and ensures that it is both understood and used (Paul and Whittam 2010). The gatekeeper role thus relies on the ability to leverage many external and internal connections, which suggests that it is not possible to simply assign someone to this role (Nochur and Allen 1992). Skills important to a gatekeeper include having an in-depth technical understanding, and the ability to repackage and communicate knowledge (Cillo 2005). The differences between boundary spanning in regard to organisations and parts of organisations are not well understood (Marrone 2010), but enough similarities have been noted to suggest that they are not completely distinct roles (Tushman 1977b). For instance, the transfer of knowledge within firms into different parts of the organisation by organisational liaisons seems to follow the same two-step process as observed in regard to gatekeepers.

\subsection{Organisational culture and innovation}

Organisational culture is a broad field, which has been conceptualized and studied in many different ways (Schein 1990; Fisher and Alford 2000). Nevertheless, Schein's (1990) perspective of organisational culture as shared values and assumptions manifesting themselves in an organisations' artefacts and day-to-day activities is often adapted in the innovation discourse (Martins and Terblanche 2003; Hartmann 2006; Al Saifi 2015). Organisational culture and innovation are thus often related through the way the former supports the latter (Martins and Terblanche 2003; Hartmann 2006; Al Saifi 2015). However, the implications of such a broad concept as organisational culture stretch beyond setting the stage for behaviour-it also implies an influence on the artefacts that come out of the innovation process (Al Saifi 2015).

There are several categorization schemes for identifying types of innovation. Rowley et al. (2011) merge many of these schemes by mapping them onto the framework by Francis and Bessant (2005), which in turn discerns between four types of innovation targeting-product, process, position and paradigm. Most schemes provide finer details on the product and process innovation targets, i.e., types of innovation that either change the artefacts offered by an organization, or how these artefacts are created or delivered. Gopalakrishnan and Damanpour (1994) instead discern between technical and administrative innovations. The former relates to product and process innovations concerned with produced artefacts and delivery processes, while the latter relates to process innovations concerned with organisational structure and administrative processes. Different types of innovation have been related to different parts of organisations, i.e., their technical and administrative cores (Daft 1978). Technical innovations are generated by the technical core of firms, and thus face an iterative, often political, process towards adoption (Gopalakrishnan and Damanpour 1994; Elenkov and Manev 2005). The generation of administrative innovations can be influenced by a wide set of internal and external stakeholders, but the adoption is ultimately decided upon by the administrative core of the firm (Gopalakrishnan and Damanpour 1994; Elenkov and Manev 2005). This supposedly means that administrative innovations are likely to see less opposition than technical innovations, since the executives in the administrative core are also able to use their control over resources such as organisational culture to pave the way for innovations (Gopalakrishnan and Damanpour 1994). In this paper we will refer to the product and administrative types of innovations, as our results do not put us in a position to discuss other kinds. However, as will be shown in sub Sect. 2.3 this is enough to propose two hypotheses linked to factors relevant to cognitive systems engineering. By testing the hypotheses implications can be drawn for the safety engineering work function in socio-technical systems aimed at developing CPS.

\subsection{Implications for the safety engineering work function}

In this subsection we summarize the findings related to innovation in the two discussed discourses, and transfer them to an analytical framework related to a sociotechnical and cognitive systems engineering perspective. 


\subsubsection{Analytical framework}

An organisation's structure and culture shape the conditions under which different work functions carry out their tasks. Structure has a direct influence, while culture's influence is indirect through the socialization of shared values and assumptions. These tasks shape, among other things, an individual's skills and network, which in turn shape the knowledge held by an individual within a certain work function. This knowledge forms the primary basis on which innovation efficacy and foci are determined. However, evidence also suggests that tasks directly influence at least innovation foci, with a firm's administrative and technical core focusing on different types of innovation. These relationships, supported by literature, are visualized in Fig. 1 .

Arguably these relationships are bidirectional. A work function shapes the individual's ability and focus in innovation activities through the skills, networks and knowledge it imparts, but it also provides a specialized understanding of organisational structure and culture. In other words, the tasks of a work function will concern itself with parts of organisational structure and culture, and it is these parts that an individual will be most likely to gain an understanding of. The discourse on communities of practice provides evidence in this direction: these communities do not only provide opportunities for innovation on shared challenges, but also introduce practitioners to experts, established practitioners and others related to their work (Lesser and Storck 2001); and while absorbing tacit knowledge in regard to all parts of the organisational culture allows employees to innovate without explicit communication, each community of practice within a firm can develop their own version of this tacit knowledge and associated practices (Leonard and Sensiper 1998).

\subsubsection{Product innovation and safety engineering}

Safety engineers occupy a privileged role in CPS engineering, since safety is both heavily regulated and often seen as

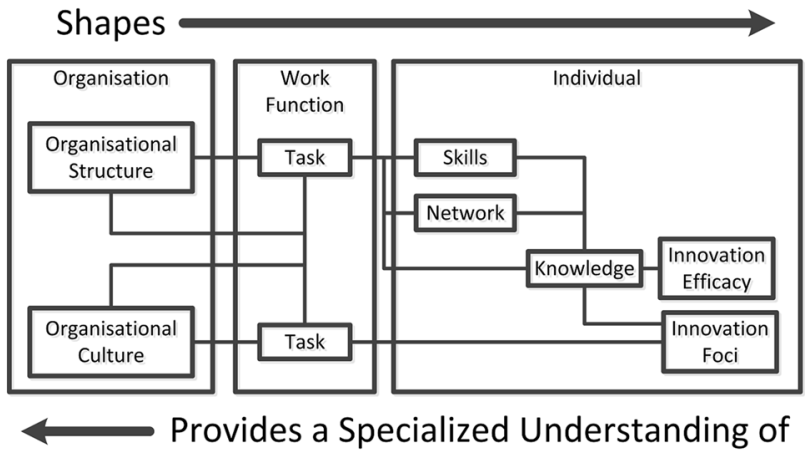

the primary product property to get right (Geisberger et al. 2015; Törngren et al. 2017). The safety function starts its work with a system-wide perspective, eventually breaking down and allocating responsibilities for ensuring safety. This is typically done as an integrated part of system engineering's technical, and technical management processes, and in cooperation with many other teams and engineering functions (International Electrotechnical Commission 2010; SAE S-18 Aircraft and Systems Development and Safety Assessment Committee 2010; International Organization for Standardization 2011). A common problem that has to be solved by this work is the dissonance (Ruault et al. 2013) or gap of mental models (Norman 1986) between different engineering disciplines and those who will use product functions. Similarly to system engineering, the safety engineering work function thus requires engineers to act as organisational liaisons, expanding their network by spanning boundaries between engineering disciplines. This allows them to eliminate dissonance by transferring knowledge from one part of the organisation to another, or by explaining the novel potential of old knowledge from experience elsewhere. It also means that safety engineers need to acquire sufficiently deep technical knowledge to communicate with (and sometimes direct) experts. Therefore, even if the safety engineering work function is not part of the technical core, we could reasonably expect safety engineers to understand enough to be able to produce product innovations. Furthermore, with the system-wide starting point comes the need to adopt a system-oriented approach (Rasmussen 1997). This type of approach, captured in engineering by the concept of systems thinking, involves being able to consider a complex system in a holistic way (Behl and Ferreira 2014). The enablers to the development of systems thinking among engineers include experience across external and internal boundaries, strong interpersonal skills, and curiosity and open-mindedness (Davidz 2006). It is thus reasonable, in so far as the organisational culture at a firm encourages sharing information, to expect safety engineers in particular to seek out, be privy to and act on technical knowledge internal to a firm that is useful to product innovation.

We thus expect the safety engineering work function to shape its members networks, knowledge and skills to enable technology brokering towards product innovation. We suggest the following hypothesis:

H1 Safety engineers will be suited to facilitating the realization of product innovation by transferring and transforming knowledge across boundaries between organisational units and engineering disciplines.

Fig. 1 Analytical framework 


\subsubsection{Administrative innovation and safety engineering}

In CPS engineering, the safety engineering work function is also tasked with seeing that no untoward influence affects the processes meant to ensure safety. This might be manifested in terms of behaviour-shaping constraints due to the fact that management often has a limited view of work as done, often referred to as work as imagined (McDonald 2015; Hollnagel 2017). This thus involves dealing with organisational issues such as leadership, communication, risk perception, teamwork, normalisation of deviance and learning (Lockwood et al. 2015). This non-technical work is essentially meant to shape the safety culture of the organisation, i.e., "those aspects of the organisational culture which will impact on attitudes and behaviour related to increasing or decreasing risk" (Guldenmund 2000). Safety culture is related to the concept of culture as discussed in several scientific discourses, but shares a similar background to the way the concept of culture has been approached in the innovation literature (Edwards et al. 2013). Still, the concept is not uncontroversial in safety science, with fundamental issues such as whether it can be managed or measured remaining the subject of ongoing debate (Haukelid 2008; Grote 2012). This controversy is often based in different conceptualizations, such as it being "best practice", shared standards or value-based practices (Edwards et al. 2013). On the one hand, one can thus find instrumental approaches in which safety culture is seen as straightforward to change, even though several studies suggest that psychological factors can render attempts to control culture difficult (Haukelid 2008). On the other hand, one can find anthropological approaches which fail to perceive the effect of contextual factors on behaviour regardless of the values and beliefs of those studied (Edwards et al. 2013). However, safety culture holds a unique position among cultural aspects, as it is difficult to envision situations in which a negative outcome in the form of a catastrophic event is acceptable. There are thus strong reasons for treating safety culture as a leading indicator (Grote 2012), necessitating a focus on the whole causal chain from norms to behaviour among safety practitioners. The efforts by safety engineers towards safety culture can thus be directed at different levels of organisational culture, i.e., throughout the range from basic assumptions to artefacts (Guldenmund 2000) - meaning that we can expect safety engineers to be involved in associated tasks ranging from setting up inspections to imprinting upon newly hired engineers the importance of being diligent about risk. This should facilitate a deep understanding of organisational culture, especially as related to safety.

There are also several aspects of the safety engineering work function that make safety engineers well positioned to make sense of the organisational context, even if their interest is limited to safety. Apart from the aforementioned favourable conditions for developing a systems thinking perspective and crossing boundaries, there is also their relationship to the rules that organisations use to govern safety. There are well-founded arguments for two different perspectives on how rules best ensure safety, i.e., by being able "to define and guide behaviour in complex and often conflicting environments and processes" or by acting as "supports, not strait jackets; as tools to coordinate and structure creativity and innovation, not as controls to limit freedom" (Hale and Borys 2013b). Much suggests that the former perspective is the most common among top management (Hale and Borys 2013a), which implies that safety engineers would be in a position to directly learn about their organisational context as subject experts providing input to rule-making. However, there are various industries that need to rely on the ability of operators to actively detect and steer their organisation away from unsafe situations (Rasmussen 1997; Dekker 2006; Hale and Borys 2013b), which is rather aligned with the latter perspective. In high reliability organisations this has been shown to ingrain itself into the organisational culture: collegial patterns of authority combined with wellinformed decentralised decision making then come to rest on operators who are willing to act in a highly autonomous way within their local domain (La Porte 1996). Hale and Borys (2013a) provide a benchmark for good practice in the form of a framework for leveraging both of these perspectives, using dialogue through first-line supervision to reconcile the implied conflict between operators as domain experts and safety engineers as subject experts. Indeed, this good practice might already exist to some degree in workplaces, but remain undetected by a too narrow academic discourse (Pilbeam et al. 2016). Pilbeam et al. (2016) suggest as much by highlighting that safety compliance in practice implies involvement by many different actors and a wider set of activities than monitoring adherence to rules. This involvement would likely extend to safety engineers as other employees seek support in maintaining safety while adhering to the spirit of the rules. This type of continuous engagement would place safety engineers in a position to learn about their organisational context. In essence, this is reminiscent to approaches meant to gain a thorough understanding of work practices, such as the way participatory design involves the intended users in a development process as part of the design team (Kujala 2003). The central and coordinating role of safety engineers gives them insight into the behaviour-shaping constraints of the work system of interest, which is that of the engineers developing CPS products.

We can thus expect the safety engineering work function to, under most circumstances, facilitate the understanding of organisational aspects, such as: what the shared beliefs are; the formal and informal structures that build networks between employees; and whose authority is applicable in 
given situations. We posit that this happens most strongly in regard to the aspects of organisational culture that relate to safety culture. Given the strong focus on safety in CPS engineering, ensuring this property is likely to be one of the primary organisational values of firms developing CPS. We suggest the following hypothesis:

H2 Safety engineers will, through their specialized understanding of organisational culture, be suited to facilitating the realization of administrative innovations.

\section{Research design and methods}

This paper draws on analyses of the activities across 4 years on an online platform for firm-internal innovation collaboration, as well as interviews with those participating in said activities. The study follows a sequential explanatory strategy by first establishing quantitative results and then interpreting them by use of qualitative results (Creswell 2013). The following three subsections introduce the context of the study before discussing the details and validity of each part of it.

\subsection{Research context}

The firm on which the study is based is a multi-national engineering company developing Cyber-Physical Systems (CPS). CPS enable interaction with physical processes through information technology, and include technical products throughout domains such as aerospace, automotive, marine and nuclear. The firm has about 50,000 employees in 150 countries, developing products for both civil and defence purposes. Engineering is organised into organisationally separate business sectors focused on different domains. However, certain functions and initiatives have an enterprise-wide reach, such as aspects of capability and innovation management.

One such initiative with enterprise-wide reach is an online platform for firm-internal innovation collaboration, henceforth called the Innovation Portal (InnP). The InnP has roughly 23,000 registered users of which about 4500 have been more or less continuously active. Active users belong to all parts of the firm, for instance the engineering, financial, factory, project management and secretarial functions. All of the continents on which the firm is present are represented, for instance by users from Australia, Canada, Chile, England, Germany and India. However, as might be expected, the user base reflects the demographics of the firm in that engineers from the largest sites make up a large percentage.

The InnP was designed to allow employees to propose or influence ideas in domains they would otherwise be isolated from. It achieves this through internal crowdsourcing, where users collaborate to generate, develop and evaluate ideas (Zuchowski et al. 2016). This starts when a challenge sponsor advertises an engineering or organizational problem on the InnP. All users are then asked to generate ideas for solutions to the problem via the platform. Of the provided ideas ten are chosen by the InnP administrators for the crowd to develop through commenting and "thumbing up/down". Eventually the involvement of the crowd ends with InnP users evaluating ideas through voting: each vote involves ranking ideas by repeatedly choosing the better idea in pairings generated by the InnP. Ideas selected by the crowd are then evaluated and possibly selected for implementation by representatives of the administrative core of the Firm, i.e., the challenge sponsor and an independent team of experts.

Each of these activities brings its own creative and democratic benefits. For example, a more decentralised evaluation of ideas by users from several domains could ensure that prejudice by leaders does not hinder idea uptake. As of today 5529 ideas have been submitted to the InnP. 147 of these have, in competition with the others, been selected and implemented. This has affected both the products developed by the Firm and its administrative processes. However, as our hypotheses are related to the facilitation of ideas, we focus on the developing activities, where users support the elaboration of the ideas they find most useful. In other words, we are primarily interested in the situation visualized in Fig. 2: after an employee at the firm submits an idea, other employees facilitate its development across organisational boundaries by aggregating knowledge gained through the tasks they carry out within their work functions. (Other activities are also considered, but from the perspective of adequately handling threats to validity. This is described in detail in sub Sect. 3.2.)

We note that the safety engineering work function at the Firm includes engineers that work with very different tasks, for instance focusing on reliability, human factors, and liaising with regulators. As indicated by our theoretical framework we posit that the important mechanism is

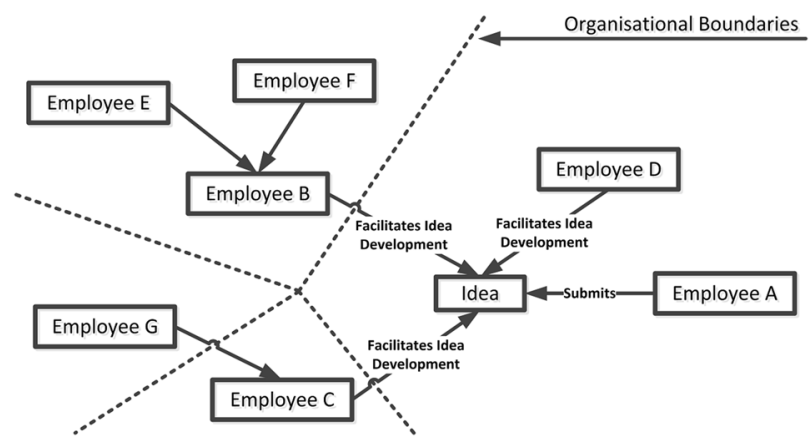

Fig. 2 Collaboration across organisational boundaries 
that the work function constitutes an informal community that shapes its members. Specific individuals in the safety engineering work function might be better or worse than others at facilitating innovation in line with either of the two hypotheses: a safety engineer with human factors engineering tasks might for instance acquire more skills and contacts related to $\mathrm{H} 2$ than a safety engineer with reliability engineering tasks. However, both will take part in informal discussions and negotiation of practice within the work function, which should lead to a common understanding in line with the two hypotheses. This should show itself when testing the hypotheses on the group, if not the individuals.

\subsection{Quantitative analysis of InnP activities}

Two of the activities on the InnP provide opportunities to evaluate the hypotheses, i.e., the "thumbing up/down" and the commenting on ideas. "Thumbing up/down" does not provide any information on why an idea is seen as good or bad, but in this context it is primarily an input to the voting. In other words, for the hypotheses it does not matter why a user "thumbed up/down", as the purpose of this action in this context is to signal that the user believes the merits of the idea to clearly outweigh its disadvantages or vice versa. A significant difference between safety engineers and others in "thumbing up" of ideas eventually selected for implementation thus suggests that they were better at identifying the ideas eventually favoured by the Firm, while a significant difference for "thumbing down" indicates the opposite. Similarly, a significant difference between safety engineers and others in regard to commenting on ideas eventually selected for implementation also indicates that they were better at identifying the ideas eventually favoured by the Firm, as commenting suggests a willingness to help refine an idea. Therefore, significant differences in regard to "thumbing up" and commenting would signal that the associated types of ideas are examples of opportunities that safety engineers were especially well placed to grasp, while a significant difference in "thumbing down" would indicate the opposite. Ideally this type of test is performed using a One-Way ANOVA. However, the data sets contained outliers, as assessed by inspection of a boxplot, and were not normally distributed, as assessed by Shapiro-Wilk's test $(p<0.05)$. This means that the characteristics of the data motivated the use of a Mann-Whitney $U$ test to establish differences between the groups (Sheskin 2004; Ryan 2013a).

The submission of ideas can be analysed to support the interpretation of the study: whether safety engineers are more prone to submit winning ideas will indicate whether any relationship to opportunities is direct or indirect. The Chi square goodness-of-fit test is used for this purpose (Sheskin 2000).
The voting on ideas can be analysed to support the validity of the study: if safety engineers vote more often on winning ideas, this might indicate that they are not better at identifying good opportunities, but rather at pushing their ideas through. This applies to both their own voting, and that of those they communicate with on the InnP. Again, this type of test is ideally performed using a One-Way ANOVA. However, while the data sets did not contain outliers, as assessed by inspection of a boxplot, none of them were normally distributed, as assessed by Shapiro-Wilk's test $(p<0.05)$. This means that the characteristics of the data motivated the use of Mann-Whitney $U$ tests.

\subsection{Interviews and qualitative analysis}

Three of the interviewees were safety engineers active on the InnP, since the study focused on the safety engineering work function. As the purpose of the interviews was to support the interpretation of quantitative results relating to collaboration between multiple work functions, seven InnP users from other work functions were interviewed-these had all strongly contributed to ideas that safety engineers had contributed to via the activities described in the previous subsection and were connected to the network of safety engineers on the InnP. Furthermore, to get an overview of the innovation process at the studied firm, three administrators tasked with defining and overseeing the InnP process were also interviewed. In total, 13 people were interviewed: three administrators and ten InnP users deemed (from their activities on InnP) to have good insights into both the crowdsourcing and innovations of interest to safety engineers. The sampled interviewees should thus be able to provide a thorough understanding both of the relevant activities on the InnP and different perspectives on how the safety engineering work function engages with innovation.

The interview investigation was performed according to the seven stages described by (Kvale and Brinkmann 2009): from thematising and designing the investigation; through conducting, transcribing and analysing the interviews; to verifying and reporting the results.

With the overall purpose and design of the study as outlined previously, the detailed design phase of the interviews focused further on threats to validity. The largest threat in this regard was deemed to be interviewees self-censoring themselves when their opinions did not align with the rest of their organisation. Interviewees could also be reluctant to share sensitive information if they believed it could be released publically in an uncontrolled way. Therefore, the confidentiality of the interviews was stressed repeatedly, and results followed up with the interviewees prior to publication. The latter effort was included in the study as repeated member checks to further support the validity of the results 
(Creswell and Miller 2000). The results from these checks have been incorporated into the discussion section.

The interviewing phase started with the creation of a detailed interview script. The first part of the script covered the mechanics and motivations for the different activities of the crowd by asking interviewees to describe their own and others' engagement with each activity on the InnP. Followup questions were prepared for each activity, focusing on the capabilities of those involved, the motivation behind engaging, and confounding factors that might affect engagement. The second part of the script focused on the collaboration on the InnP, and in particular whether this collaboration could be affected by the networking of the safety engineering work function. As the outcomes of any collaboration were not known in detail, this part of the interview was based on asking for the opinions of the interviewees-a priori prepared follow-up questions were then used to link opinions to concrete outcomes. Each interview lasted about $1 \mathrm{~h}$, and all but one was conducted face-to-face. All interviews were recorded, transcribed and coded. Coding was first descriptive (Saldaña 2009a), resulting in about 200 descriptive codes. Each code was entered into a codebook together with a short explanation. In this way each new instance of a code could be checked against both previous instances and its established meaning. This ensured that the coding was consistent and stayed close to the interviews. The coding then focused on identifying patterns (Saldaña 2009b), which were transformed into categories with a bearing on the research questions through discussions among the authors. This discussion served to ensure that the interpretations of the interviews remained true to the interviewees' responses, and were not the subjective interpretation of a single researcher. In line with the overall design of the study to use qualitative results to interpret quantitative results, the categories were primarily formed based on eliciting motivations to engage with the InnP that could be linked to concrete outcomes associated with the hypotheses. As an example, as safety as an organisational value is important to both hypotheses, patterns that supported or disconfirmed its importance in activities at the studied firm were noted as they appeared during analysis. Furthermore, patterns that might indicate that the outcome of the InnP would be skewed by the participants, the types of ideas or the innovation process at the firm were pursued, as this might also influence the interpretation of the quantitative results.

\section{Results}

This section presents the results from the study, starting with the quantitative outcomes and continuing with the qualitative outcomes to further refine the findings. Summaries are given at the end of each subsection and table.

\section{1 “Thumbs Up/Down” assessment of ideas}

Two Mann-Whitney $U$ tests were performed to determine whether safety engineers differed in the amount of thumbing up or down of ideas eventually selected for implementation. Analysis was performed on those that engaged with this activity. Distributions were not similar, as assessed by visual inspection. The amount of thumbing down by safety engineers (mean rank $=337.96$ ) and other work functions (mean rank $=324.00)$ was not statistically significantly different, $U=7.497, z=0.698, p=0.485$. The amount of thumbing up was statistically significantly higher by safety engineers (mean rank $=393.48$ ) than in other work functions (mean rank $=321.96), U=8774, z=2.226, p=0.026$. However, the effect size of the later test was trivial, $r=0.087$.

Safety engineers did not engage more strongly with ideas eventually selected for implementation using the "thumbs up/down" assessment of ideas.

\subsection{Comments on ideas}

A Mann-Whitney $U$ test was run to determine whether safety engineers differed in the amount of commenting on ideas eventually selected for implementation. Analysis was performed on those that engaged with this activity. Distributions were not similar, as assessed by visual inspection. The amount of commenting was statistically significantly higher by safety engineers (mean rank $=105.45)$ than in other work functions (mean rank $=71.15$ ), $U=999.5, z=2.726$, $p=0.006$. The effect size was small, $r=0.23$.

Safety engineers commented more strongly on ideas eventually selected for implementation.

\subsection{Submission of ideas}

5529 ideas had been submitted to the InnP at the time of analysis, of which 147 had been chosen for implementation. 227 of the ideas had been submitted by safety engineers, of which 6 had been chosen for implementation. 1.78\% of the submitters of ideas were safety engineers. Two Chi square goodness-of-fit tests were conducted to determine whether proportions were different from what could be expected:

- The first test analysed the proportion of ideas submitted by safety engineers to the proportion expected based on their percentage of all submitters. The minimum expected frequency was 98 . The Chi square goodness-of-fit test indicated that the number of ideas submitted by safety engineers was not the expected one based on the safety engineers' proportion of submitters $\left(\chi^{2}(1)=170.793\right.$, $p<0.01$ ).

- The second analysed the proportion of ideas submitted by safety engineers and chosen for implementation 
to the proportion expected based on the proportion of ideas submitted by safety engineers. The minimum expected frequency was 6 . The Chi square goodness-offit test indicated that the number of ideas submitted by safety engineers and chosen for implementation was the expected one based on the proportion of ideas submitted by safety engineers $\left(\chi^{2}(1)=0, p=0.988\right)$.

Safety engineers submitted relatively more ideas than other work functions, but their ideas did not have an unexpectedly high rate of success.

\subsection{Voting on ideas}

The crowd voting was performed on pairs of ideas. Users were thus not asked to vote on their favourite ideas, but on the superior of two that the InnP presented. Therefore, the voting score was measured as the proportion of votes on ideas chosen for implementation in the pair-wise votes involving one such idea and one not chosen for implementation. (Therefore, a user that voted 8 times in votes involving one idea that was eventually implemented and one that was not, and in these votes voted 4 times for the implemented idea, would have a voting score of 0.5 ). Analysis was performed on those that engaged with this activity and on those ideas that the safety engineers had engaged with through commenting.

First a test compared safety engineers to all other voters. Distributions were similar, as assessed by visual inspection. The median voting score for safety engineers $(0.63)$ and other work functions $(0.57)$ was not statistically significantly different, $U=20,331, z=0.250, p=0.803$.

Subsequently a test compared the safety engineering network, i.e., the safety engineers and all those they had communicated with on the InnP, to all other voters. Distributions were similar, as assessed by visual inspection. The median voting score for the safety engineering network (0.59) and others $(0.57)$ was not statistically significantly different, $U=128,591, z=-0.400, p=0.689$.

To claim that a null hypothesis should not be rejected, the sample size must be ensured to be sufficiently large. A Mann-Whitney $U$ Test is frequently used with small sample sizes, but has less power than its parametric counterpart. Furthermore, it is difficult to establish a required sample size for this method (Ryan 2013b), but as a rule-of-thumb it can be done using its parametric counterpart and adding an extra $15 \%$ to the sample size. A statistical significance of 0.05 and a statistical power of 0.8 were chosen. The voting score was expected to vary quite a lot, but anything other than a large difference in means was also deemed irrelevant. Therefore the effect size was based on an estimated standard deviation of 0.25 , and a difference in means larger than 0.25 . The required sample size was then calculated to 20 respondents in the smallest group, which the sample met without problems.

Safety engineers were not better at pushing their ideas through to implementation, neither by themselves nor through their immediate network. The ideas chosen for implementation that they engaged with can thus be used to measure what type of opportunities they were especially well placed to grasp.

\subsection{Ideas commented on by safety engineers}

The ideas that were eventually chosen for implementation and which safety engineers engaged with through commenting can be put into categories relevant for $\mathrm{H} 1$ and $\mathrm{H} 2$. This is done in Table 1 using separate categories, thereby providing a description of the opportunities supported by safety engineers. It should be noted that only $7 \%$ of the

Table 1 Categories of ideas supported by safety engineers

\begin{tabular}{lc}
\hline Description & $\begin{array}{c}\text { Percentage } \\
\text { of ideas (\%) }\end{array}$ \\
\hline Business & 4 \\
Diversity (supporting the understanding of minorities, etc.) & 4 \\
Leadership & 4 \\
Outreach (presentations at engineering schools, compiling material for activities outside of the firm, etc.) & 7 \\
Related to safety engineering (technical issues) & 7 \\
Related to non-safety engineering (technical issues) & 14 \\
Social (setting up meeting places, motivating employees, etc.) & 18 \\
Communication (when to communicate, how to communicate efficiently, setting up communication technology, etc.) & 21 \\
Health and wellbeing (opportunities for varying the work environment, physical activities, etc.) & 21
\end{tabular}

As predicted by $\mathrm{H} 2$, safety engineers seem well placed to support the realization of administrative innovations associated with aspects of organisational culture related to safety, such as leadership, teamwork, communication and human factors. However, we find no evidence to support the $\mathrm{H} 1$ prediction that safety engineers would be especially adept at supporting the realization of product innovations due to their boundaryspanning activities 
engineering-related ideas required a deep understanding of details to engage with, and none of the ideas was a technology brokering idea that rested on bringing together different engineering disciplines.

\subsection{Facilitating the interpretation}

When analysing the interviews, categories were identified in relation to the participants on the InnP, the ideas on the InnP and the InnP itself. These are presented together with exemplifying excerpts from the interviews in Tables 2, 3 and 4, respectively. A summative explanation of the categories is given in each table. As noted in the previous section-the responses are not only from safety engineers, but rather represent strong categories across all interviewees. In this way we can support the interpretation of the quantitative results from the perspective of all those involved in this part of the collaborative innovation.

\section{Analysis and discussion}

This section positions the results before generalizing their managerial implications for innovation and safety culture. Thereafter the most obvious limitations of the study are reflected on, especially in regard to directions for future research.

\subsection{Analysis}

As predicted by $\mathrm{H} 2$, safety engineers contributed significantly more than other work functions to the elaboration of administrative innovations related to the parts of organisational culture that they had specialized knowledge of. They did this by being supportive and aligned with both management and other participants on the InnP, rather than taking the lead: they did not submit and push through these ideas on their own, and they were acutely aware of the expectations of the organisation regarding administrative innovations. From a socio-cultural perspective the innovation process on the InnP in regard to administrative innovation can thus be seen as organisational learning, where different work functions come together to construct new working practices (Engeström 2001). More specifically the InnP can be seen as a forum for an important part of organisational learning, which is to enable the creation of shared meaning (Boreham and Morgan 2004). The InnP in this respect operates as a vehicle for communication across communities of practice, which has been shown to support radical innovation by neutralizing resistance from any single professional group (Swan et al. 2002). Users are given hierarchical authorization when a problem is advertised, while the discussion in relation to solutions provides co-authorization (Vanderhaegen and Jimenez 2018). The InnP is thus comparable to other digital platforms, such as IT-systems for safety reporting, that can act as tools for organizational learning and facilitate a positive impact on safety culture (Sujan 2012). Similarly to the way a reporting system can expose latent factors for safety risks (Sujan 2012), the InnP can expose ideas that help change behaviour-shaping constraints for engineers in a CPS development firm.

Indeed, the InnP was seen by the interviewees as a way to collectively circumvent hierarchies that might otherwise be daunting to confront. What safety engineers did well was thus to identify and support administrative innovations that were viable and valuable from the administrative core's perspective and the inner workings of current working practice. From the perspective of cognitive systems engineering, safety engineers can thus be seen as knowing enough about the behaviour-shaping constraints at the firm that they can identify viable ways to improve them. Firstly, they can identify how for instance social and organizational factors put up barriers to the flexibility of work functions. Secondly, they can identify administrative innovations that would remove these barriers, and which would be accepted by management.

\subsection{Implications}

This subsection discusses the implications of the results, first in regard to the safety engineering work function and then in regard to work functions in general.

\subsubsection{Managing safety through organizational learning}

To fully address safety in complex socio-technical systems, the associated work system and its relational structures need to be understood. This means that, in addition to designing work tasks, one must also create shared work support systems. This allows individual decisions and activities distributed in time and across an organisation to be based on shared mental models and shows how these contribute to an emergent whole (Rasmussen 2000). While safety culture can be perceived as a vague concept, safety engineers often engage with it directly through such shared safety management systems. These systems define indicators that allow organisations to drive the change of operational processes and demonstrate safety performance. In the aviation domain the introduction of effective safety management in operations is seen as a strategic priority to improve on the already low number of incidents (European Aviation Safety Agency 2017). Here not only firms involved in operations, but also engineering firms focused on research and development, have come out in open support for this priority by signing up to regulation no. 376 of the European Union (2014). This regulation stipulates, for example, that a "just 
Table 2 Example quotations regarding the participants

Personal drive

"A: No, fair enough. So we've got this off-topics, social issues, leadership, outreach, diversity, so do you feel capable in assessing those kinds of topics, if they were innovated on-

B: Well maybe yeah, because to a certain extent that'd be more as me, me as a person rather than me as a, you know, this [corporate] communication..."

"Well I mean I kind of, well I understand we're sort of short of engineers in general, yeah and it would be nice to kind of reduce, kind of address the gender imbalance of engineering, because it's actually quite shocking, I find it quite shocking actually"

"Because I feel passionately that, you know, the young generation-you know, the young children are sort of future engineers. We need to encourage them to think about engineering as a career. We need to show them how exciting engineering can be"

"I think it's important for people to give their ideas in what they think is a good place to work because it demonstrates how people would feel comfortable in their workplace"

"Yeah, it's partly the work experience. It's partly personal experience outside of work as well. I referred to my medical condition..."

Professional responsibility “... they should have a responsibility for doing the best they can and taking, yeah, I don't know, whatever you want to call it, ethics and environmental and all those other things that say well actually I've got the — and obviously responsibility to the company as a whole"

"I don't think I could ever go and work for a tobacco company because I think that would-I don't think I would square that circle of sending a product that I thought was harmful to people but..."

"Yes. I think we're all responsible for the things that we do. We have to be responsible for the materials and innovations we come up with for the future and future generation. So that links back to sustainability and environmental behaviour"

"So your professional responsibility to [Firm] is to deliver a quality product that's safe that meets the customer requirements, is efficient, etc., the whole raft of different criteria around it. You've got to take professional responsibility for delivering that"

"Because I think most engineers realise — well certainly if you're working in this industry that what you do needs to be right because of, you know, if you make a mistake that can, you know, could be catastrophic ... and there's just the general sense of kind of pride in what you do, that you want to be professional, you know, you are a professional person and therefore you want to behave in a professional manner, through your own sense of self-worth really"

Safety in numbers

"Safety is important, and [Firm] clearly encourages and supports us to challenge each other regardless of position... safety matters, and I have seen that myself first hand. Some are hesitant to act alone though ... it takes more from them to go ahead..."

"Yes, whether they would is a different matter. So if I saw [Firm CEO] walking somewhere, for example, I don't know, carrying a hot coffee upstairs without a lid, would I challenge him? Over something like that, probably, but many people probably wouldn't for fear of reprisals"

"Maybe it's difficult. I mean maybe it depends on, you know, maybe I've haven't got an A-type personality and stuff, which is, kind of explains where I am in life and stuff. I mean people have, you know more A-type personalities or whatever, it might be they go and talk to people higher up the organisation, but ..."

"But that's about the relationships you've built up over the years, isn't it? So it's more difficult I guess at the-for lower down the sort of pecking order you feel you are. So if you're a-you know, an [Pay Grade] who's just joined the company you might feel you're not really able to challenge a senior leader"

“... there's still that stigma of, you don't necessarily want to raise an issue or challenge a manager because of what they could possibly do to you in terms of your career and stuff"

"I think one person on their own can find it difficult because you get-it's personal opinion some of it. But if you've got a team of fourteen of you and three of you think the same thing then I think you've got more influence because it's a common train of thought"

"But I think it's titles that do it. Someone in a team will go to their manager, their team leader. But when you get things like director, executive, chief, some people sort of aren't as easy going that high up. I don't think it's the people that aren't approachable, I don't think it's the organisation that stops it, I think people see a title. I think if they saw the name rather than a title they'd go, oh yeah I'll go and talk to them" 
Table 2 (continued)

Safety as a core value

"Because if you don't take responsibility you've always got at the back of your mind not only the monetary side but more importantly the safety of all the people out there. And a slight mistake on the designs or the manufacture of a part in our [product] could lead to a disaster"

"[Initiative] is one of the biggest initiatives we have in the business, which is zero safety incidents. It has to be. Certainly within the area I work in, safety is absolutely number-one priority. It's absolutely critical. ... They tell us it's very important, but we also realise on a daily basis how important safety is within — certainly within an industrial environment and the environment we operate in, everything is-everything we do is governed by safety or security, ... even to the point where you don't cross roads where you're not meant to. You hold handrails when you walk downstairs. You don't carry hot coffee. Simple things but done-have to be done well"

"He can lead rather than manage, if that makes sense. So by communicate-by being aware of his own limitations as a communicator and improving them through the innovation of leadership, he can lead better and make sure that the safety culture and the sharing and the knowledge is evident or is passed down through his team and his people he works for or work for him"

“... every year or two we have to do this online learning about all the, who's respons- I did it, just did it recently again, this online learning stuff, so there is, there is commitment to sort of product safety and stuff"

"You know, we've got a duty to put out a product which is safe and just-in my mind just meeting the regulations is a small part of that. You know, we have to think more widely about, you know, what — practically how can we reduce the risk as low as we can?"

"The amount of double, triple checking that goes on, you know, the way they control information in documents is just staggering, they really are, safety's just right at the top of the issue. You can't change or move anything without getting the right authority, just because of the potential impacts on the [CPS Product], so it's an interesting one, then does it make you more risk adverse because that's safety culture's so strong and evasive? I think maybe in some ways it does, but that doesn't mean those people aren't creative, and perhaps if they'd had the time and the route, the mechanism to get engaged with innovation, maybe they could even be, because they're almost like frustrated around not being able to be perhaps as creative as they might want to be, you've given them this opportunity, this door opens into, maybe they'd be a great source to tap into"

"A: Well, because it (pause) you know, we have a-I think an obligation to society. So, you know, if you- we have an obligation to our work force so, you know, there are issues that affect our work force so, you know, whether working hours or mental health or whatever it might be; general sort of health and wellbeing, those sort of things that affect our employees. Our products certainly impact on the environment, you know, so there is a wider implication there. So I think we have an obligation to society to make our products safe and so I think there's (pause) some compatibility between the technical issues and some of the social-our social conscience

B: Which comes from your engineering outlook-

A: I think it does partly. And that sort of idea that you know, I come to work to have a good time and I want other people to enjoy coming to work as well"

A motivation to contribute to ideas seems to have come from the personal experiences or circumstances of the interviewees. Contributing to ideas on the InnP was also seen as an easier way to effect change than confronting issues directly in the workplace. However, the most powerful motivation stemmed from the emphasis interviewees placed on acting professionally in line with the principles of engineering, the Firm and society as a whole. As noted by several interviewees, this motivation was aligned to the organisational culture of the Firm as it emphasised the production of safe products

Table 3 Example quotations regarding the ideas

Firm alignment "Well, for [technical area] the majority come from people submitting forms, because the [InnP], in order to get ideas you have to pose a problem. So, if you never put any problems up, you'll never get any ideas"

“... certain [Firm] leaders with their experiences and skills have a similar impact in terms of their personality and what they believe, whether that's subconscious or consciously ... So if they're interested in a topic they're more likely to put a challenge related to that topic"

"I think a lot of the ideas go along with what the company strategy is"

"Usually what gets chosen at the end by the sponsor will be something that's in line with what the company wants to do"

"I think at the minute if I'm honest, as soon as it's outside of our business product portfolio we probably just park them. I don't think we follow them through perhaps as much, as more rigorously as we should"

The interviewees were clear on the fact that ideas were eventually evaluated according to the shared beliefs and policies of the Firm. It would be futile to support an idea not aligned to these, as such ideas would not be implemented even if they won the vote

culture" should be promoted as a basis for a robust safety management system. [This support stems from examples of the possible implications of not connecting the safety culture of an engineering firm to the design and manufacture of its products for use in high risk environments, see for instance (Vicente 2003)].

Unfortunately, the positive influence of safety management systems can be cancelled out by political, social and 
Table 4 Example quotations regarding the InnP

Part of the picture ".. they might well do that rather than submit to the innovation portal ... because- to be honest, because everybody wants
to put their own name to their own patent, don't they?"
"there are ... people I collaborate with on a regular basis through other forums... but I think the innovation portal is a wider
mix of expertise so you get a sort of different opinion which is not a bad thing"
"So actually, another reason I might not submit an idea is if I think it's patentable and I can see my way to it; in which case
what I'll do is send an email to our patents engineer and then get it registered before I put anything on"

The interviewees also noted that the InnP was only one way through which innovation takes place in the Firm. Other aspects of the safety engineering role might come through in other ways used to harness innovation

methodological issues as different parts of an organisation fail to align work practices and priorities (Ulfvengren and Corrigan 2015). The result is a safety management system that does not function as a whole, since organisational behaviour-shaping constraints inappropriately limit the ways employees can act. This is especially likely in firms providing safety-critical operational services: with safety departments and senior to middle management normally not being (safety) engineers, there is a risk of a lack of a system perspective among those designing a safety management system (Reiman and Rollenhagen 2011). This could lead to the needs and requirements of those with a stake in ensuring safety being ignored. The introduction of a safety management system can also easily become a top-down exercise, where focus is solely on ensuring that it is possible to gather, aggregate and analyse safety-relevant data. However, a safety management system requires not only effective information handling, but also the competence to draw conclusions and the willingness to implement reforms (International Civil Aviation Organization 2013).

In our results most of the engagement with administrative innovations by the safety engineering work function was not to support safety, but their ability to identify viable innovations of this type could most likely be put to this use. Our results suggest that safety engineers could thus be effective at filling a mediatory role between different work functions and the administrative core in regard to administrative innovation. As such they could identify which innovative changes to organisational structures and administrative processes would be acceptable across the organisation when introducing and operating a safety management system. In essence, safety engineers could reach out across the organisation to identify and support ways to loosen behaviourshaping constraints in ways appreciated by those carrying out the work, rather than acting on safety-related problems by designing solutions solely from their own, or a management, perspective.

\subsubsection{More innovative work functions}

With work practice as the basis for the identified ability of safety engineers to facilitate administrative innovation, the possibility to instil this ability into other work functions using the same mechanism seems remote. As per the logic applied to creating gatekeepers (Nochur and Allen 1992), the best option might be to identify work functions with a similar aptitude and appropriately strengthen their skills and networking. Arguably the identification of such work functions will be specific to each firm, as the work functions most strongly tied to the organisational culture will depend on each firm's organisational values. Nevertheless, some skills and networking could be universally useful for the identification and facilitation of this type of administrative innovation, and thus appropriate to strengthen regardless of the work function in question. We suggest, based on the safety engineering work function studied and system engineering principles, that these should include organisational liaising and systems thinking.

Barriers to communication become important in this type of facilitation of administrative innovation, as it entails one work function identifying and engaging with ideas from other work functions. From a networking perspective this context would be perceived as having a low degree of homophily (Rogers 1995), i.e., many of the participants in the innovation process would be dissimilar to each other. Indeed, meaningful communication between multiple communities of practice seems to depend on overcoming a communication threshold since it is positively related to active efforts to integrate knowledge but negatively related to mere passive acceptance of differences (Ishiyama 2016). As boundary spanners such as organisational liaisons have a motivation for engaging in heterophilous communication, it stands to reason they will have more of an opportunity to become skilled at it, which could explain part of the ability of the safety engineers in this study. A first step to develop likely work functions to better facilitate this type of administrative innovation could thus be to increase the organisational liaising that is part of their work tasks. However, the previously mentioned imperative among safety engineers to interact with others in the role of subject expert during rule-making could also have been an important antecedent in this regard, since it motivates the more active efforts to integrate knowledge found to be important by Ishiyama (2016). A second step could thus be to increase the motivation to actively integrate the knowledge of other work functions in boundary spanning tasks, for instance by rewarding positive 
outcomes or highlighting the business criticality of failing to spot issues.

These groups can also, at an organisational level, be analysed from a political perspective (Tushman 1977a). From this perspective the partitioning of an organisation may create its own logic in a firm, leading to a self-reinforcing cycle where employees increasingly try to control and limit the flow of information between the different parts (Vince 2001). Organisational learning thus not only relies on shaping individuals and teams capable of learning, but on an understanding of the organisation as a complex system where shared visions, mental models, team learning and personal mastery is integrated by systems thinking (Senge 1990a; Vince 2001). At its most basic level this means that well-functioning organisational learning rests on individuals that have learnt how to look for a broader perspective when cooperating in a team (Senge 1990b). If organisational liaising provides the context for engaging in heterophilous communication and organisational values the motivation for active engagement, then systems thinking could thus presumably be what provides the tools for making this engagement successful in the face of political resistance. This could be an explanation for the safety engineers' ability to successfully support the facilitation of administrative innovation in an environment where the organisation eventually decides viability. A third step to develop likely work functions to better facilitate this type of administrative innovation could thus be to further train them in systems thinking tools (Monat and Gannon 2015).

\subsection{Limitations and future work}

The primary limitation of this study is that it relies on the success of the InnP as self-reported by the firm and the interviewees. We have identified a relationship between the safety engineering work function and facilitation of ideas found viable by other employees and the Firm. However, the Firm and interviewees might have misunderstood the real outcome of implementing these ideas, which could be without an effect or even counterproductive. This is unlikely as the InnP relies on input from those directly involved in the work affected, and as the ideas are evaluated prior to implementation by an independent team of experts and a challenge sponsor. In fact, as we are not studying the ideas or their outcomes but rather how they are handled, the latter evaluation allows us to state that the safety engineers can identify viable innovation. In other words, even if the ideas that the hypotheses were tested against were, objectively speaking, not the optimal ones, they were the best of those that the organisation could accept. Furthermore, in general, studies have shown that the efficacy of crowdsourcing is on par with that of problem solving by experts (Poetz and Schreier 2012).
As related studies have rather focused on analysing CPS per se (Vanderhaegen and Jimenez 2018), the novel perspective of this study, to define the system of interest as the work system of a firm developing CPS technology, should be attractive to the research community. It is also important as this broader view of work and organization promises to contribute to the "humanization" of the field of system engineering towards human-system integration (Hoffman et al. 2009; Boy 2017). Additional research to establish important phenomena and relationships in this context should, and will most likely, be carried out (Hoffman et al. 2009; von Krogh et al. 2012; Boy 2017). Below we elaborate on some of the possible directions for this, based specifically on the need to study important factors where they differ from our context, i.e., in more organisations.

Another limitation is that this study only considered the collaboration on the InnP. As mentioned by the interviewees, there were other ways through which innovation was channelled by the firm, for instance a patenting process. This might explain the lack of support for $\mathrm{H} 1$, since product innovation is easier to patent than administrative innovation. The supportive role of safety engineering also offers a possible explanation, since it does not necessarily lead to sufficiently deep technological knowledge to enable viable product innovation or come with enough power to overcome resistance to a "not invented here" attitude. Further investigations could aim to establish whether the hypothesis should definitely be discarded, or whether there are opportunities for management to intervene to further support product innovation in this type of context.

Even though safety engineers were better at elaborating administrative innovation eventually deemed viable by the Firm, they did not generate more viable administrative innovations on their own. There are several possible reasons for this, but the most interesting is perhaps that safety culture is a broad enough concept that not all of it may be encompassed by organisational values even if safety is deemed important in general. If that was the case in the studied Firm then several valuable administrative innovations might have been submitted by the safety engineering work function, but then rejected by either other work functions or the administrative core. To be fair, this would be the case for any administrative innovation not in line with organisational values, regardless of its source. Nevertheless, further investigation would be required to understand differences in opportunities and barriers between the generation and elaboration of administrative innovation by work functions with well-aligned specialized knowledge.

Creating shared meaning also takes time and effort: the studied data was accumulated over 4 years by several thousand users in the stable environment of a large multi-national firm. The safety engineering work function had a consistent presence, with an experienced workforce operating 
continuously with no large turnover of personnel. The discourse that the analytical framework builds on highlights the relationship between the skills, networks, knowledge and specialized understanding of organisational structure and culture imparted by a work function, but it does not define how this relationship might evolve over time to affect organisational learning. As an example, the retirement of a generation of safety engineers might pave the way for new skills, restructure networks and bring in new knowledge, but it might also decrease the safety engineering work function's understanding of and ability to work with other work functions. The latter might be tied to the decrease of certain work tasks in a firm, such as human factors engineering tasks. Further investigation would thus be required to understand the factors that strengthen or diminish the ability of a work function to facilitate innovation.

\section{Conclusions}

Belonging to a work function requires one to carry out certain work tasks, which provide and shape knowledge, skills and networks - ultimately providing a specialized, work function specific, perspective on the structure and culture of one's firm. We conclude that this influence can be strong enough to allow those work functions that provide their members with a perspective well aligned with their firm's organisational values to instil the ability to identify and support administrative innovation. Essentially those belonging to such work functions acquire the ability to facilitate organisational learning, helping different work functions to come together to construct new working practices. This suggests that safety engineers in CPS domains could be effective in a mediatory role, facilitating innovative changes to organisational structures and administrative processes when introducing and operating safety management systems. Even though instilling this ability in work functions not aligned with existing organisational values seems remote, this study suggests that stronger aspects of organisational liaising and systems thinking could at least reinforce this ability in those belonging to well-aligned work functions - the former by a wider scope and motivation leading to an increased skill in heterophilous communication, and the latter by providing the skills and tools needed to analyse the politics of complex organisations.

Acknowledgements Open access funding provided by Royal Institute of Technology. Special thanks go to Vicki Derbyshire for her help in proofreading.

\section{Compliance with ethical standards}

Conflict of interest The authors declare that they have no conflict of interest.
Open Access This article is distributed under the terms of the Creative Commons Attribution 4.0 International License (http://creativeco mmons.org/licenses/by/4.0/), which permits unrestricted use, distribution, and reproduction in any medium, provided you give appropriate credit to the original author(s) and the source, provide a link to the Creative Commons license, and indicate if changes were made.

\section{References}

Aalbers R, Dolfsma W, Koppius O (2013) Individual connectedness in innovation networks: on the role of individual motivation. Res Policy 42:624-634

Al Saifi SA (2015) Positioning organisational culture in knowledge management research. J Knowl Manag 19:164-189

Amabile TM (1997) Motivating creativity in organizations: on doing what you love and loving what you do. Calif Manag Rev 40:39-58

Aral S (2016) The future of weak ties. Am J Sociol 121:1931-1939

Behl DV, Ferreira S (2014) Systems thinking: an analysis of key factors and relationships. Proc Comput Sci 36:104-109

Boreham N, Morgan C (2004) A sociocultural analysis of organisational learning. Oxf Rev Educ 30:307-325

Boy GA (2017) Human-centered design of complex systems: an experience-based approach. Des Sci 3:e8

Brown JS, Duguid P (2001) Knowledge and organization: a socialpractice perspective. Organ Sci 12:198-213

Burt RS (2004) Structural holes and good ideas. Am J Sociol 110:349-399

Cillo P (2005) Fostering market knowledge use in innovation: the role of internal brokers. Eur Manag J 23:404-412

Cohen WM, Levinthal DA (1990) Absorptive capacity: a new perspective on learning and innovation. Adm Sci Q 35:128-152

Creswell JW (2013) Chapter 10, mixed methods procedures. In: Quesenberry SK (ed) Research design: qualitative, quantitative, and mixed methods approaches. Sage Publications

Creswell JW, Miller DL (2000) Determining validity in qualitative inquiry. Theor Pract 39(3):124-130

Daft RL (1978) A dual-core model of organizational innovation. Acad Manag J 21:193-210

Davidz HL (2006) Enabling systems thinking to accelerate the development of senior systems engineers. Massachusetts Institute of Technology, Massachusetts

De Weck OL, Roos D, Magee CL (2011) From inventions to systems. In: De Weck OL (ed) Engineering systems: meeting human needs in a complex technological world. Mit Press, pp 1-22

Dekker S (2006) Resilience engineering: chronicling the emergence of confused consensus. Resil engineering: concepts and precepts. Ashgate, Surrey, pp 77-92

Edwards JR, Davey J, Armstrong K (2013) Returning to the roots of culture: a review and re-conceptualisation of safety culture. Saf Sci 55:70-80

Elenkov DS, Manev IM (2005) Top management leadership and influence on innovation: the role of sociocultural context. J Manag 31:381-402

Engeström Y (2001) Expansive learning at work: toward an activity theoretical reconceptualization. J Educ Work 14:133-156

European Aviation Safety Agency (2017) European Plan for Aviation Safety (EPAS), 2017-2021. European Aviation Safety Agency, Cologne

Fisher CJ, Alford RJ (2000) Consulting on culture: a new bottom line. Consult Psychol J Pract Res 52:206

Foss NJ, Minbaeva DB, Pedersen T, Reinholt M (2009) Encouraging knowledge sharing among employees: how job design matters. Hum Resour Manag 48:871-893 
Francis D, Bessant $\mathbf{J}$ (2005) Targeting innovation and implications for capability development. Technovation 25:171-183

Geisberger E, Broy M, Cengarle MV, Keil P, Niehaus J, Thiel C, Thönnißen-Fries H-J (2015) CPS thematic areas. In: Geisberger E, Broy M (eds) Living in a networked world: integrated research agenda cyber-physical systems (agendaCPS). Verlag, München, pp 73-106

Gopalakrishnan S, Damanpour F (1994) Patterns of generation and adoption of innovation in organizations: contingency models of innovation attributes. J Eng Technol Manag 11:95-116

Grant RM (1996) Prospering in dynamically-competitive environments: organizational capability as knowledge integration. Organ Sci 7:375-387

Grote G (2012) Safety management in different high-risk domainsall the same? Saf Sci 50:1983-1992

Guldenmund FW (2000) The nature of safety culture: a review of theory and research. Saf Sci 34:215-257

Haas A (2015) Crowding at the frontier: boundary spanners, gatekeepers and knowledge brokers. J Knowl Manag 19:1029-1047

Hale A, Borys D (2013a) Working to rule or working safely? Part 2: the management of safety rules and procedures. Saf Sci $55: 222-231$

Hale A, Borys D (2013b) Working to rule, or working safely? Part 1: a state of the art review. Saf Sci 55:207-221

Hargadon A, Sutton RI (1997) Technology brokering and innovation in a product development firm. Adm Sci Q 42:716-749

Hartmann A (2006) The role of organizational culture in motivating innovative behaviour in construction firms. Constr Innov $6: 159-172$

Haukelid K (2008) Theories of (safety) culture revisited-an anthropological approach. Saf Sci 46:413-426

Hoffman RR, Norman DO, Vagners J (2009) Complex sociotechnical joint cognitive work systems? IEEE Intell Syst 24:c82-c83

Hollnagel E (2017) Why is work-as-imagined different from work-asdone? In: Wears RL, Hollnagel E, Braithwaite H (eds) Resilient health care, vol 2. CRC Press, Boca Raton, pp 249-264

International Civil Aviation Organization (2013) Safety management manual (SMM), 3rd edn. International Civil Aviation Organization, Montréal

International Electrotechnical Commission (2010) BS/IEC 61508:2010, functional safety of electrical/electronic/programmable electronic safety-related systems. International Electrotechnical Commission, Geneva

International Organization for Standardization (2011) ISO 26262 Road vehicles-functional safety. International Organization for Standardization, London

Ishiyama N (2016) Role of knowledge brokers in communities of practice in Japan. J Knowl Manag 20:1302-1317

Kujala S (2003) User involvement: a review of the benefits and challenges. Behav Inf Technol 22:1-16

Kvale S, Brinkmann S (2009) Interviews: learning the craft of qualitative research interviewing. SAGE Publications, Thousand Oaks

La Porte TR (1996) High reliability organizations: unlikely, demanding and at risk. J Conting Crisis Manag 4:60-71

Leonard D, Sensiper S (1998) The role of tacit knowledge in group innovation. Calif Manag Rev 40:112-132

Lesser EL, Storck J (2001) Communities of practice and organizational performance. IBM Syst J 40:831-841

Lockwood F, Canham R, Wright M (2015) Developing a framework for assessing workplace and product safety culture in BAE systems. In: Parsons M, Anderson T (eds) Twenty-third safety-critical systems symposium. Safety-Critical Systems Club, Bristol

Marrone JA (2010) Team boundary spanning: a multilevel review of past research and proposals for the future. J Manag 36:911-940

Martins E, Terblanche F (2003) Building organisational culture that stimulates creativity and innovation. Eur J Innov Manag 6:64-74
McDonald N (2015) The evaluation of change. Cognit Technol Work 17:193-206

McDonald N, Ulfvengren P (2019) Governance, complexity and deep system threats. In: REA Symposium on Resilience Engineering Embracing Resilience

Meister D (ed) (1999) Introduction to HFE. In: The history of human factors and ergonomics, CRC Press, Boca Raton

Monat JP, Gannon TF (2015) What is systems thinking? A review of selected literature plus recommendations. Am J Syst Sci 4:11-26

Nochur KS, Allen TJ (1992) Do nominated boundary spanners become effective technological gatekeepers? (technology transfer). IEEE Trans Eng Manag 39:265-269

Nooteboom B (2000) Learning by interaction: absorptive capacity, cognitive distance and governance. J Manag Gov 4:69-92

Norman DA (1986) Cognitive engineering. In: Norman DA, Draper SW (eds) User centered system design: new perspectives on human-computer interaction. CRC Press, Boca Raton. https:// doi.org/10.1201/9780367807320

Ozman M (2009) Inter-firm networks and innovation: a survey of literature. Econ Innov New Technol 18:39-67

Paul S, Whittam G (2010) Business angel syndicates: an exploratory study of gatekeepers. Venture Cap 12:241-256

Pilbeam C, Doherty N, Davidson R, Denyer D (2016) Safety leadership practices for organizational safety compliance: developing a research agenda from a review of the literature. Saf Sci $86: 110-121$

Poetz MK, Schreier M (2012) The value of crowdsourcing: can users really compete with professionals in generating new product ideas? J Prod Innov Manag 29:245-256

Pyka A (2002) Innovation networks in economics: from the incentive-based to the knowledge-based approaches. Eur J Innov Manag 5:152-163

Rasmussen J (1997) Risk management in a dynamic society: a modelling problem. Saf Sci 27:183-213

Rasmussen J (2000) Human factors in a dynamic information society: where are we heading? Ergonomics 43:869-879

Rasmussen J, Pejtersen AM, Goodstein LP (1994a) Analysis of work organization and system users. In: Sage AP (ed) Cognitive systems engineering. Wiley, New York

Rasmussen J, Pejtersen AM, Goodstein LP (1994b) Work domain analysis. In: Sage AP (ed) Cognitive systems engineering. Wiley, New York

Reiman T, Rollenhagen C (2011) Human and organizational biases affecting the management of safety. Reliab Eng Syst Saf 96:1263-1274

Rogers EM (1995) Diffusion networks. In: Rogers EM (ed) Diffusion of innovations, 4th edn. The Free Press, New York

Rowley J, Baregheh A, Sambrook S (2011) Towards an innovationtype mapping tool. Manag Decis 49:73-86

Ruault J-R, Vanderhaegen F, Kolski C (2013) Sociotechnical systems resilience: a dissonance engineering point of view. IFAC Proc $15: 149-156$

Ryan TP (2013a) Chapter 10, nonparametric methods. Sample size determination and power. Wiley, Hoboken, pp 323-339

Ryan TP (2013b) Nonparametric methods. Sample size determination and power. Wiley, Hoboken

SAE S-18 Aircraft \& Systems Development and Safety Assessment Committee (2010) ARP4754A: guidelines for development of civil aircraft and systems. SAE International, Warrendale

Saldaña J (ed) (2009a) First cycle coding methods. In: The coding manual for qualitative researchers. SAGE Publications Ltd, pp $45-148$

Saldaña J (ed) (2009b) Second cycle coding methods. In: The coding manual for qualitative researchers. SAGE Publications Ltd, pp 149-184 
Schein EH (1990) Organizational culture: what it is and how to change it. In: Human resource management in international firms. Springer, pp 56-82

Senge PM (1990a) Give me a lever long enough ... and singlehanded i can move the world. The fifth discipline. Currency Doubleday, New York, pp 3-16

Senge PM (1990b) Team learning. The fifth discipline. Currency Doubleday, New York, pp 233-270

Sheskin DJ (2000) Test 8. The Chi square goodness-of-fit test. In: Wood S (ed) Handbook of parametric and nonparametric statistical procedures. Chapman and Hall/CRC

Sheskin DJ (2004) Test 12: Mann-Whitney $U$ Test. In: Handbook of parametric and nonparametric statistical procedures. Chapman and Hall/CRC

Sujan MA (2012) A novel tool for organisational learning and its impact on safety culture in a hospital dispensary. Reliab Eng Syst Saf 101:21-34

Swan J, Scarbrough H, Robertson M (2002) The construction of 'Communities of Practice' in the management of innovation. Manag Learn 33:477-496

Teigland R, Wasko M (2009) Knowledge transfer in MNCs: examining how intrinsic motivations and knowledge sourcing impact individual centrality and performance. J Int Manag 15:15-31

Törngren $\mathrm{M}$ et al (2017) Characterization, analysis, and recommendations for exploiting the opportunities of cyber-physical systems. In: Song H, Rawat DB, Jeschke S, Brecher C (eds) Cyber-physical systems. Elsevier, pp 3-14

Tushman ML (1977a) A political approach to organizations: a review and rationale. Acad Manag Rev 2:206-216

Tushman ML (1977b) Special boundary roles in the innovation process. Adm Sci Q 22:587-605
Ulfvengren P, Corrigan S (2015) Development and implementation of a safety management system in a lean airline. Cognit Technol Work 17:219-236

Union European (2014) L122, regulation (EU) No 376. European Union, Brussles

Vanderhaegen F, Jimenez V (2018) The amazing human factors and their dissonances for autonomous cyber-physical and human systems. In: First IEEE conference on industrial cyber-physical systems, Saint-Petersbourg, Russia, pp 14-18

Vicente KJ (1999) Cognitive work analysis: toward safe, productive, and healthy computer-based work. CRC Press, Boca Raton

Vicente KJ (2003) What does it take? A case study of radical change toward patient safety. Jt Comm J Qual Saf 29:598-609

Vince R (2001) Power and emotion in organizational learning. Hum Relat 54:1325-1351

von Krogh G, Rossi-Lamastra C, Haefliger S (2012) Phenomenonbased research in management and organisation science: when is it rigorous and does it matter? Long Range Plan 45:277-298

West J, Bogers M (2014) Leveraging external sources of innovation: a review of research on open innovation. J Prod Innov Manag 31:814-831

Zuchowski O, Posegga O, Schlagwein D, Fischbach K (2016) Internal crowdsourcing: conceptual framework, structured review, and research agenda. J Inf Technol 31:166-184

Publisher's Note Springer Nature remains neutral with regard to jurisdictional claims in published maps and institutional affiliations. 